\title{
Vehicle Speed and Length Estimation Errors Using the Intelligent Transportation System with a Set of Anisotropic Magneto-Resistive (AMR) Sensors
}

\author{
Vytautas Markevicius ${ }^{1}$, Dangirutis Navikas ${ }^{1}$, Adam Idzkowski ${ }^{1,2}{ }^{\oplus}$, Donatas Miklusis ${ }^{1}$, \\ Darius Andriukaitis ${ }^{1, * \mathbb{D}}$, Algimantas Valinevicius ${ }^{1}$, Mindaugas Zilys ${ }^{1}$, Mindaugas Cepenas ${ }^{1}$ \\ and Wojciech Walendziuk ${ }^{2}$ (D) \\ 1 Department of Electronics Engineering, Kaunas University of Technology, Studentu St. 50-439, \\ LT-51368 Kaunas, Lithuania; vytautas.markevicius@ktu.lt (V.M.); dangirutis.navikas@ktu.lt (D.N.); \\ a.idzkowski@pb.edu.pl (A.I.); donatas.miklusis@ktu.edu (D.M.); algimantas.valinevicius@ktu.lt (A.V.); \\ mindaugas.zilys@ktu.lt (M.Z.); mindaugas.cepenas@ktu.lt (M.C.) \\ 2 Faculty of Electrical Engineering, Bialystok University of Technology; Wiejska St. 45D, \\ PL-15351 Bialystok, Poland; w.walendziuk@pb.edu.pl \\ * Correspondence: darius.andriukaitis@ktu.lt; Tel.: +370-37-300-519
}

Received: 5 November 2019; Accepted: 27 November 2019; Published: 28 November 2019

\begin{abstract}
Seeking an effective method for estimating the speed and length of a car is still a challenge for engineers and scientists who work on intelligent transportation systems. This paper focuses on a self-developed system equipped with four anisotropic magneto-resistive (AMR) sensors which are placed on a road lane. The piezoelectric polyvinylidene fluoride (PVDF) sensors are also mounted and used as a reference device. The methods applied in the research are well-known: the fixed threshold-based method and the adaptive two-extreme-peak detection method. However, the improved accuracy of estimating the length by using one of the methods, which is based on computing the difference quotient of a time-discrete signal (representing the changes in the magnitude of the magnetic field of the Earth), is observed. The obtained results, i.e., the speed and length of a vehicle, are presented for various values of the increment $\Delta n$ used in numerical differentiation of magnetic field magnitude data. The results were achieved in real traffic conditions after analyzing a data set $M=290$ of vehicle signatures. The accuracy was evaluated by calculating MAE (Mean Absolute Error), RMSE (Root Mean Squared Error) for different classes of vehicles. The MAE is within the range of $0.52 \mathrm{~m}-1.18 \mathrm{~m}$ when using the appropriate calibration factor. The results are dependent on the distance between sensors, the speed of vehicle and the signal processing method applied.
\end{abstract}

Keywords: magnetic field; AMR sensors; piezoelectric PVDF sensors; vehicle speed detection; car length estimation; signal differentiation; Mean Absolute Error

\section{Introduction}

In recent years many intelligent traffic systems have been created using data acquired from magnetic field sensors [1,2], which exploit the magnetoresistance (MR) effect [2] or the magnetoimpedance (MI) effect [3,4], inductive loops [5] or piezoelectric PVDF sensors [6] installed on a road lane.

By processing the measured data, not only the number of passing vehicles can be counted but also their speed, length and even weight can be estimated [7,8].

In previous works [9-11], the authors focused on developing a stationary system which was installed on a public road for measuring individual lengths and speeds and identification of vehicles. It was a built-in system operating in normal traffic conditions, which calculated parameters in real-time. Two anisotropic magneto-resistive sensors (AMR) were placed on the road lane at a distance of 
$0.3 \mathrm{~m}$ [10]. The main aim of the research was focused on the signal processing, the metrological analysis of measurement results as well as testing new algorithms aimed at reducing the calculation time of speed and length of the passing vehicles. This calculated time was shorter than $60 \mathrm{~ms}$ for each analyzed vehicle and the accuracy of estimating its speed and length was within the range of $\pm 3 \mathrm{~km} / \mathrm{h}$.

A comparative analysis of the results of the determined individual speeds of vehicles traveling in road traffic and the times of executing programs based on selected calculation methods was carried out in previously published articles [9-11] as well. To determine the speed of vehicles, the method of detecting the delay value of two signals, with respect to each other, of different computational complexity was used. The results of a comparative analysis of many algorithms for determining the speed of vehicles were developed, not only for signals with a large sample size but also for small sample size sections [10]. Linear interpolation was proposed to be applied in order to increase the resolution of the calculated speed results. On the basis of the assessment of the relative speed results average errors (related to the values read from the radar), favorable calculation methods were selected (ensuring satisfactory accuracy with a small number of samples of the processed signal).

In another work [11], the comparative measures RMSE (Root Mean Squared Error) and NRMSE (Normalized Root Mean Squared Error) of a large set of speed results of individual vehicles obtained by a selected calculation method and a reference method (a $60 \mathrm{fps}$ video camera) were developed. Four methods for detecting the delay value of two signals in relation to each other were implemented. A signal processing algorithm was developed and selected speed estimation methods were compared. The influence of changing the window width (i.e., number of samples) of the filter averaging the signals on the current basis on the size of estimated speed errors at different set threshold values of signals was investigated. The above mentioned results were obtained for two-sensor systems and it was assumed that a vehicle was passing over the sensors at a constant speed, nor accelerating or slowing down or performing steering maneuvers.

Currently, the authors propose a new solution with two-sensor pairs (Figure 1). The system assures acquiring data with a minimum distance between sensors and is placed on a road lane. Some variants of computations enable more accurate determination of speed and length of a traveling vehicle.

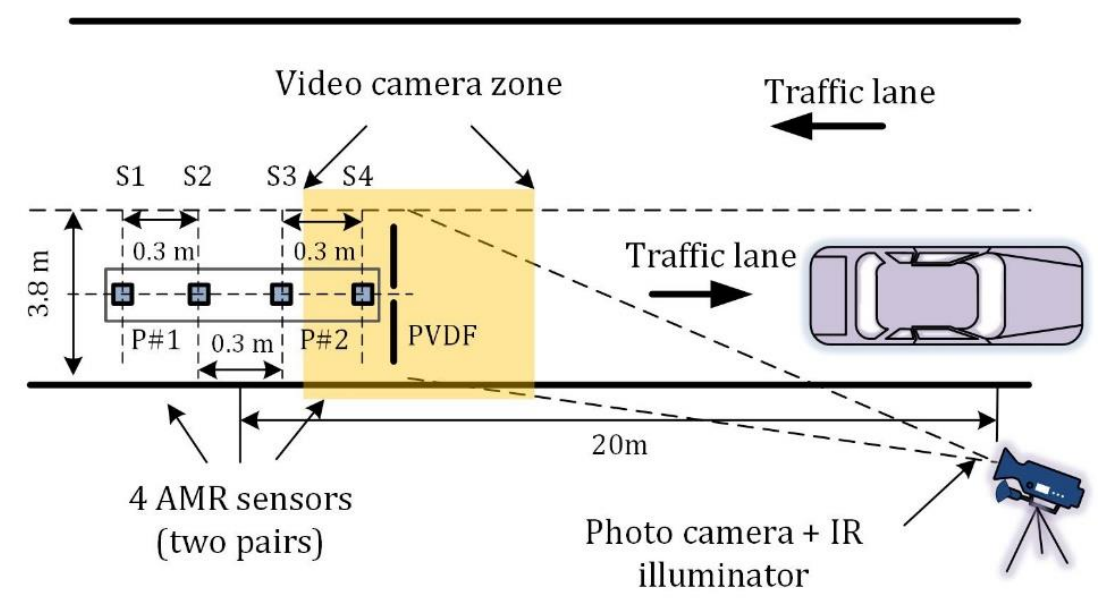

Figure 1. Deployment of traffic monitoring system components on the road (note: used scale does not keep ratio between distance in the figure and the corresponding distance on the sensors placed on the road lane, IR - infrared).

The goal of the research, presented in this paper, is to apply and verify a modified method for speed and length estimation which is based on a fixed or an adaptive thresholding of a signal. It relies on calculating the difference quotient of a time-discrete signal. The initial task was to set up an optimal value of the increment $\Delta n$ used in numeric differentiation of magnetic field magnitude data. Another goal is to show the differences in speed and length estimation errors which depend on the geometrical parameters of vehicles. 


\section{The Design of a Traffic Monitoring System and Sources of Speed Estimation Error}

The traffic monitoring system consists of hardware and software components that are placed in different locations. The magnetic and piezoelectric sensors, their cables and a video camera with infrared illuminator cannot be deployed at a large distance. The magnetic sensors S1-S4 should be placed in the middle of the traffic lane under the surface of the roadway at the beginning of the video camera zone. The general scheme of the traffic monitoring system components deployment is presented in Figures 1 and 2.

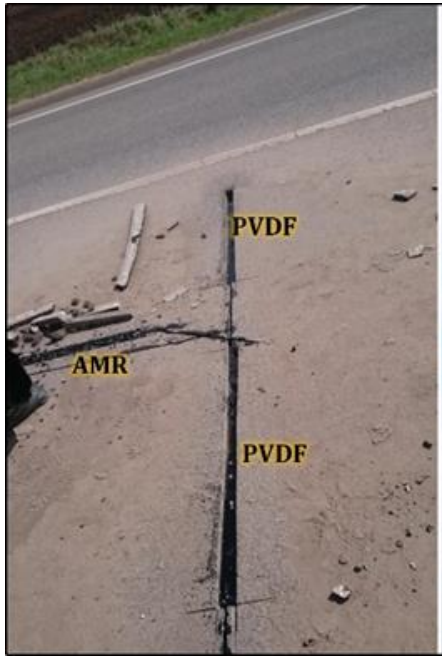

(a)

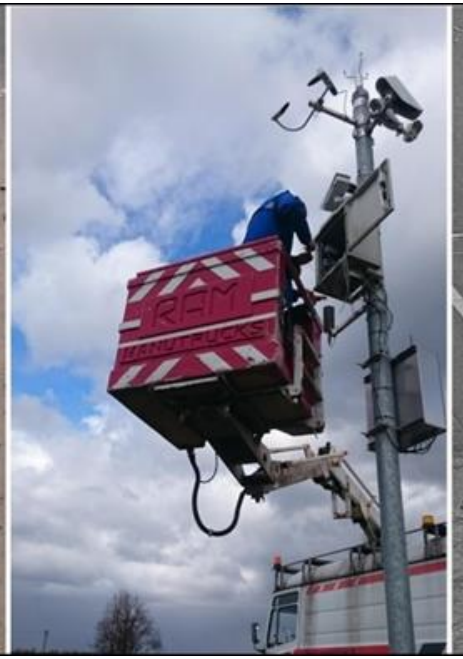

(b)

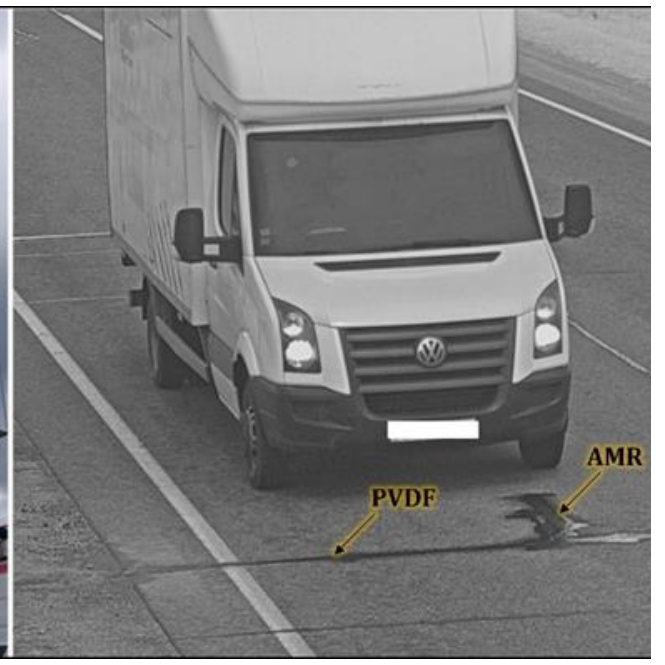

(c)

Figure 2. Deployment of traffic monitoring system components on the road $(\mathbf{a}, \mathbf{b})$ and a view from a traffic monitoring camera (c).

\subsection{Error Due to Discretization in Time}

However, there are limitations in the realization of the scheme in Figure 1, i.e., the distance between the magnetic sensors must be optimal. It is determined by several contradictory factors. The larger the distance between the sensors, the more accurately the average speed of vehicle traveling between them can be calculated (Figure 3a). The number of data points acquired during the total time elapsed is defined by the following formula:

$$
d_{p}=f_{s} \frac{D}{V}
$$

where $D$-distance between two sensor nodes $[\mathrm{m}], V$-average speed $[\mathrm{m} / \mathrm{s}], f_{\mathrm{s}}$-sampling frequency $[\mathrm{Hz}]$.

Sampling frequency should be as high as possible. Errors resulting from the manufacturing process, which cause error of $D$, should be minimum. The relative error $E$ due to discretization depends on the sampling frequency, which in this case is $2 \mathrm{kHz}$ (sampling interval $0.5 \mathrm{~ms}$ ). This error is most significant when vehicles move at higher speeds. It is defined as:

$$
E=\frac{1}{d_{p}} 100 \%
$$

Obviously, increasing the distance between the sensors reduces the sampling discretization error. This error does not exceed $1.2 \%$ when sensors are distant by $2 \mathrm{~m}$ even at $170 \mathrm{~km} / \mathrm{h}$ (Figure $3 \mathrm{~b}$ ). However, such a large distance causes a technical problem of situating the sensors at proper places, as their geometric configuration affects the measurement accuracy. 


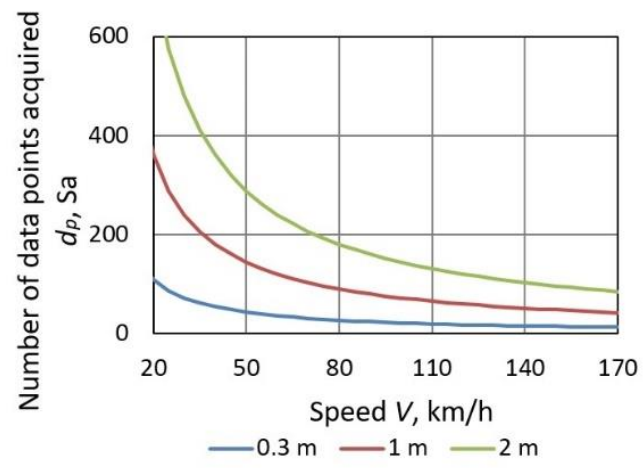

(a)

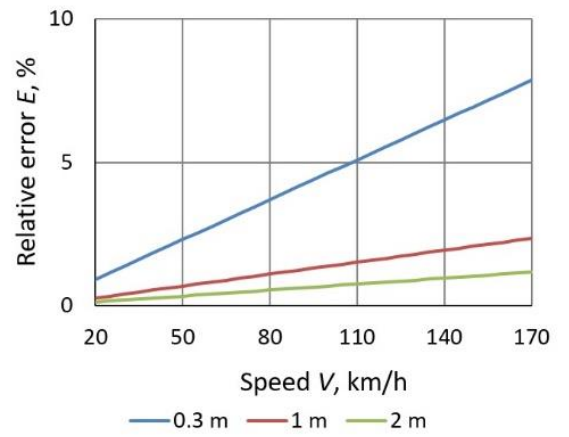

(b)

Figure 3. The number of data points acquired in the function of vehicle speed and corresponding error due to discretization (at sampling frequency of $2 \mathrm{kHz}$ ): (a) the number of data points acquired at different distances between sensor nodes; (b) relative error due to discretization at different distances between sensor nodes.

\subsection{Error Related to Vehicle Deceleration or Acceleration}

The location of sensor nodes is an important determinant of the system performance properties [12]. A single-lane configuration and a slight intrusion in the road surface were assumed. The acceptable distance between sensors is from $0.3 \mathrm{~m}$ to $1.0 \mathrm{~m}$, because with a greater distance, there is a possibility of additional errors due to a change in vehicle trajectories and accelerations. When the distance between the sensors is approximately $2 \mathrm{~m}$ and higher, the speed of a decelerating or accelerating vehicles in the sensor area will be unequal for the first magnetic sensor and the second one. These errors are less significant for vehicles at higher speeds but it should be taken into account for relatively slow moving vehicles. The average rate of acceleration of all the ordinary vehicles is between $1 \mathrm{~m} / \mathrm{s}^{2}$ and $4 \mathrm{~m} / \mathrm{s}^{2}$ [13]. Acceleration, considering real models, is varied and depends on a vehicle type and a gear number [14]. Therefore, in previous works [9-11], the obtained speed accuracy was determined within the range of $\pm 3 \mathrm{~km} / \mathrm{h}$ and the comparison to existing systems showed it was sufficient, keeping in mind that the distance between sensors was set to $0.3 \mathrm{~m}$. Due to a low sampling frequency and a short distance between sensors, the accelerating or decelerating effect will not be analyzed in the further sections of this paper.

\subsection{Trajectory Error}

If the system sensors are deployed at a distance greater than $0.5 \mathrm{~m}$, then there may be an error resulting from vehicle maneuvering (Figure 4). In a situation when a vehicle slip angle $\alpha$ is $30^{\circ}$, the relative error of the estimated length is about $15 \%$. When the cars move on trajectories whose directions do not coincide with the longitudinal axis of the magnetic sensors due to the interaction between the parts of the vehicle and the sensors, the magnetic signatures at the input and at the output of the system may be different. An error occurs when the calculating time delays on the basis of such signatures. The trajectory error may occur with improper sensors installation or due to potholes in a road surface or unknown objects which cause drivers to change direction. They force drivers to turn the steering wheel while entering the sensing area. When installing magnetic sensors in places where turning is prohibited these errors can be reduced (but not eliminated). Magnetic sensors are currently mounted on the longitudinal axis of the lane, but this does not mean that most cars move in the trajectory where the longitudinal axis of the car coincides with the central axis of the lane. In every sensor mounting location a vehicle trajectory survey should be performed to determine the optimum position of the magnetic sensors in relation to the axis of the lane. 


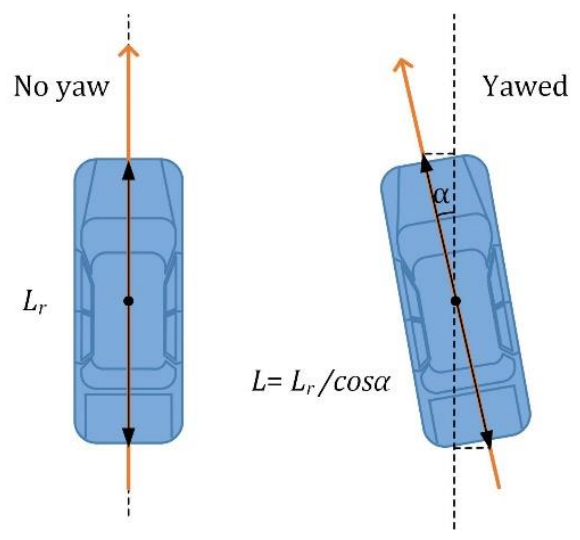

Figure 4. A situation when a vehicle is headed in a different direction than it is pointing.

\subsection{Error of Time Delay Estimation}

The magnetic flux density $B$ (the magnitude of the magnetic field) is the number of magnetic lines of force passing through a unit area of material.

The AMR sensor measures the incident magnetic field $B$ in three geometrical axes providing three corresponding components $\left(B_{\mathrm{x}}, B_{\mathrm{y}}, B_{\mathrm{z}}\right)$. The changes in the Earth magnetic field magnitude at two sensor nodes, caused by a traveling vehicle, are expressed as follows:

$$
\left|\vec{B}_{1}\right|=\sqrt{B_{1 x}^{2}+B_{1 y}^{2}+B_{1 z}^{2}}=B_{1},\left|\vec{B}_{2}\right|=\sqrt{B_{2 x}^{2}+B_{2 y}^{2}+B_{2 z}^{2}}=B_{2} .
$$

For calculating vehicle speed, it is necessary to find the time delay between two curves (data points from two AMR sensors).

The problem gets more complicated in practice as the received signal is corrupted with additive random noise. The result deeply depends on the sample size [10] and preprocessing techniques of signals (i.e., filtering, normalization). Therefore, two curves, $B_{1}$ and $B_{2}$, can be considered as signal $s$ with measurement errors $e_{B 1}, e_{B 2}$ :

$$
\begin{gathered}
B_{1}[n]=s[n]+e_{B 1}[n], \\
B_{2}[n]=s\left[n-n_{d}\right]+e_{B 2}[n],
\end{gathered}
$$

where $n$-sample number, $n_{d}$-sample delay.

It is commonly accepted, that for this purpose, cross-correlation is one of the most reliable methods [9]. The averaged time delay in seconds is the output of the cross-correlation function. It is given by the following formula:

$$
\begin{gathered}
\Delta t=\bar{n}_{d} \cdot t_{s}=\underset{l}{\operatorname{argmax}} f[l] \cdot t_{s} \\
f[l]=\sum_{n=0}^{N-1} B_{1}[n] \cdot B_{2}[n-l], \quad-(N-1)<l<N-1,
\end{gathered}
$$

where $\bar{n}_{d}$-location of the highest peak of the cross-correlation function $f$ (averaged sample delay), $t_{s}$-sampling period $\left(1 / f_{s}\right), l$-lag (a delay in samples), $N$-total number of samples in the time series.

The averaged sample delay corresponds to the average speed of a vehicle in the time interval between passing sensors S1 and S2 or sensors S1 and S4 (Figure 1). The algorithm for estimating a result variation in the presence of measurement errors is complicated. The analytical error estimation is presented in article [15]. The use of cross-correlation with Fast Fourier Transform (FFT) interpolation, parabolic fit interpolation or the FFT with Hilbert transform can diminish the error of the time delay estimation [16]. Another technique is proposed in the further section of this paper. 


\section{Methods to Estimate Vehicle Speed and Length}

\subsection{Speed Estimation Method}

The method is based on calculating derivatives of two scalar functions with respect to time. In the numerical analysis, if the samples are contained in one-dimensional (1D) arrays $B_{1}$ and $B_{2}$, then, the difference quotients $\Delta B_{1}$ and $\Delta B_{2}$ can be estimated using the equation:

$$
\Delta B_{1}[n]=\frac{B_{1}[n+\Delta n]-B_{1}[n]}{\Delta n}, \Delta B_{2}[n]=\frac{B_{2}[n+\Delta n]-B_{2}[n]}{\Delta n},
$$

where $n$-subsequent sample number in the computational algorithm, $\Delta n$-increment in $n$.

As is shown in Figure 5, the difference quotient is used to calculate the slope of the secant line between two points on the graph of functions $B_{1}$ and $B_{2}$.

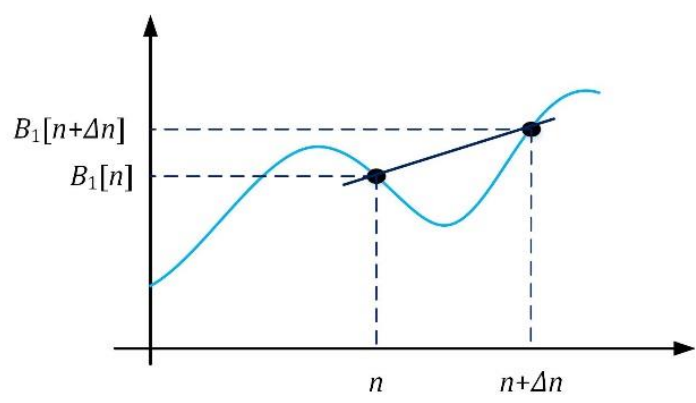

Figure 5. Finding the slope of the secant line of a magnetic field magnitude curve.

As opposed to previously published articles [9-11], it was decided to differentiate the change in magnetic field magnitude signals (Figure 6). Then, the cross-correlation function (Figure 5) with inputs $\Delta B_{1}$ and $\Delta B_{2}$ instead of $B_{1}$ and $B_{2}$ was used. Signals $B_{1}$ and $B_{2}$ were previously affected by signal smoothing with a low-pass filter $(100 \mathrm{~Hz})$. Furthermore, the increment $\Delta n$ plays a significant role in the obtained result of the speed and its accuracy. It will be presented in Section 4.

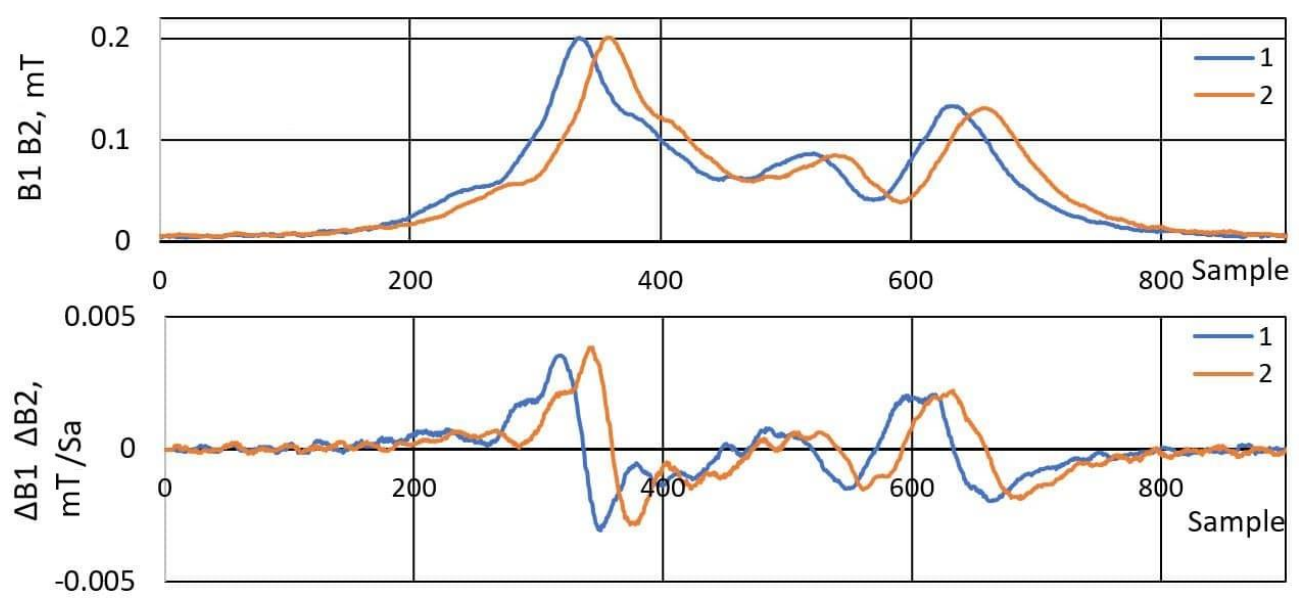

Figure 6. A pair of registered magnetic signatures from sensors S1 and S2 before and after differentiation (Volkswagen Passat 2003, sample delay—23, speed-94 km/h).

\subsection{Length Estimation Method}

Estimating a vehicle length is based on two parameters: speed and length of the signal. Since the magnetic signal magnitude rises gradually with an arriving vehicle, it is not a trivial task to accurately identify the arrival and departure moments. Several different methods were tested, and finally, it was chosen to calculate the derivative of a signal from a single sensor. The algorithm relies on the 
assumption that the first positive significant peak represents the vehicle front and the last negative peak-its rear part. This method is presented in Figure 7. Firstly, the derivative signal is obtained and normalized. Then, the peak finding algorithm is employed. It is crucial to identify the correct peak; therefore, there are two rules: the peak must be above/below a certain threshold value, moreover, the value and the location of the local maximum must be found in a set of data. The second rule enables establishing the first/last peak just above the noise level. Furthermore, since one measurement node consists of two magnetic sensors, it enables the calculation of vehicle length from two independent signals and use those result as the average.

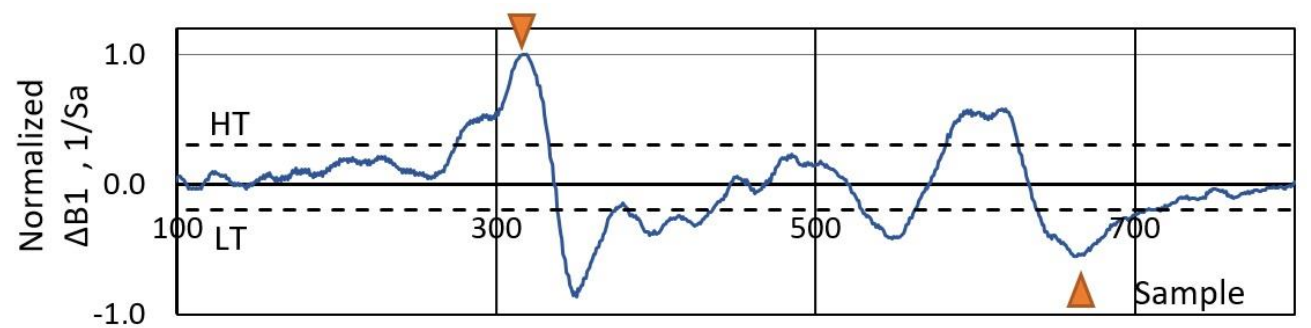

Figure 7. Vehicle length estimation $\left(L_{1}=4.40 \mathrm{~m}\right)$ based on differentiation of the signal from sensor S1. Markers indicate the first and the last significant peaks which represent a vehicle arrival and departure, respectively. HT and LT mean higher and lower threshold, respectively $\left(f_{s}=2 \mathrm{kHz}\right)$.

Figure 8 shows the full signal processing algorithm.

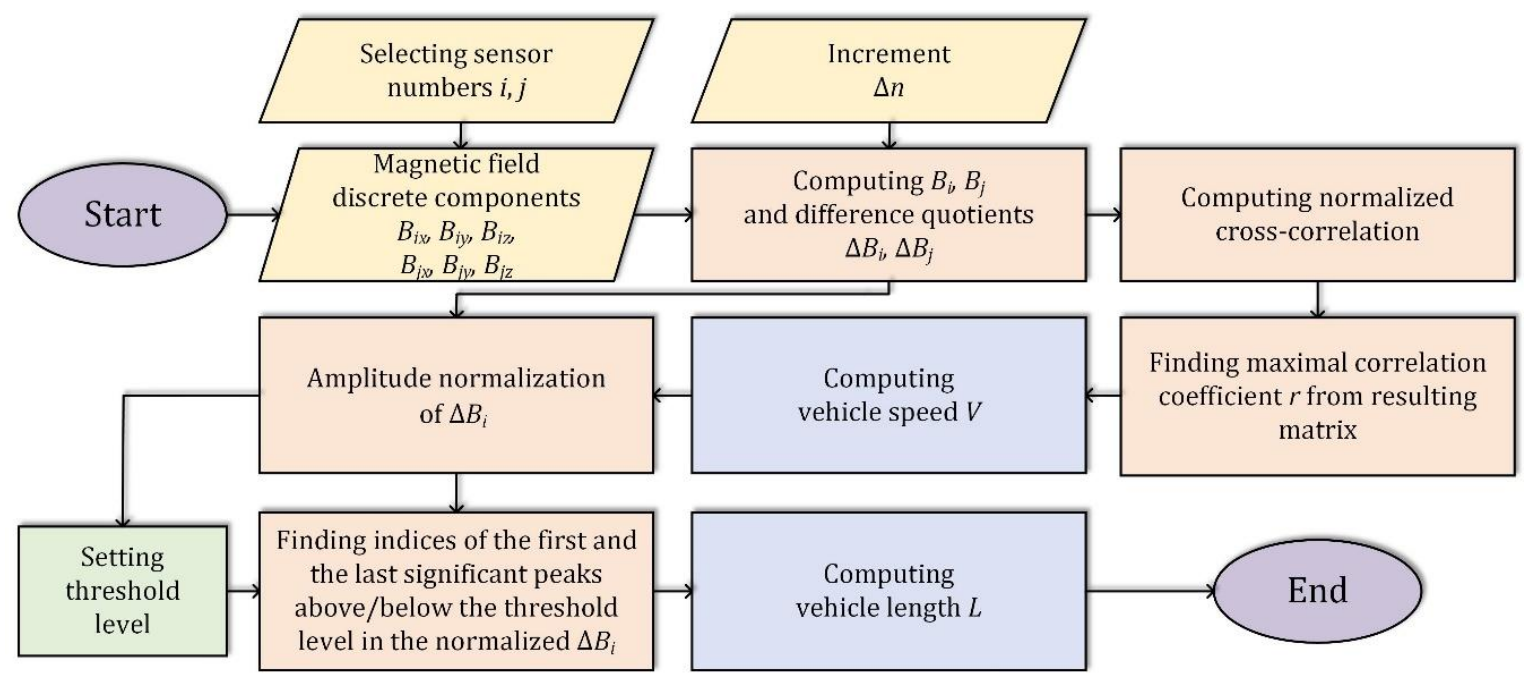

Figure 8. Algorithm for estimating vehicle speed and length.

After detecting a vehicle, the threshold HT = -LT was calculated individually for every magnetic signature based on the normalized signal $\Delta B_{i}$. For this purpose, the highest peak of this signal was found and its value was multiplied by a coefficient. This coefficient represents a percentage. The results in Section 4 are presented for the threshold of $10 \%$. 


\section{Results}

\subsection{Speed Estimation Error}

The methods mentioned in Section 3 were verified using a data set of the size of $M=290$ vehicles. The $M A E$ (Mean Absolute Error) is an absolute difference of the reference speed $V_{r}$ and the measured speed $V_{p}$, expressed by the formula:

$$
M A E_{p}=\frac{1}{M} \sum_{m=1}^{M}\left|V_{p m}-V_{r m}\right|
$$

where M-number of vehicles which equals 290, $\mathrm{m}$ - vehicle number in the data set.

It should be noted that $V_{r}$ is a value obtained due to the use of PVDF piezoelectric sensors (Roadtrax BL, Measurement Specialties Inc., Hampton, VA, USA) based on the time difference between the front and rear axles. While $V_{p}$ (for $p=1 \ldots 5$ ) is estimated by means of AMR sensors (LIS3MDL, STMicroelectronics Inc., Santa Clara, CA, USA), which are placed at the distance D (Table 1).

Table 1. The reference speed and absolute speed differences for five pairs of sensors depicted in Figure 1. Mean absolute errors for a data set of 290 vehicles of different classes.

\begin{tabular}{|c|c|c|c|c|c|c|}
\hline \multirow{2}{*}{$\begin{array}{l}\text { Vehicle } \\
\text { Number }\end{array}$} & \multirow{2}{*}{$\begin{array}{c}\text { Reference } \\
\text { Speed } V r, \mathrm{~km} / \mathrm{h}\end{array}$} & $p=1$ & 2 & 3 & 4 & 5 \\
\hline & & $\begin{array}{c}d V \_\mathrm{P} \# 1 \\
D=30 \mathrm{~cm}, \mathrm{~km} / \mathrm{h}\end{array}$ & $\begin{array}{c}d V \_\mathrm{P} \# 2 \\
D=30 \mathrm{~cm}, \mathrm{~km} / \mathrm{h}\end{array}$ & $\begin{array}{c}d V \_\mathrm{S} 2-\mathrm{S} 3 \\
D=30 \mathrm{~cm}, \mathrm{~km} / \mathrm{h}\end{array}$ & $\begin{array}{c}d V \_S 1-S 3 \\
D=60 \mathrm{~cm}, \mathrm{~km} / \mathrm{h}\end{array}$ & $\begin{array}{c}d V \_S 1-S 4 \\
D=90 \mathrm{~cm}, \mathrm{~km} / \mathrm{h}\end{array}$ \\
\hline 1 & 87.0 & 0.5 & 0.5 & 0.5 & 0.5 & 0.6 \\
\hline 2 & 94.3 & 3.9 & 3.9 & 3.9 & 0.4 & 1.0 \\
\hline 3 & 90.7 & 3.2 & 0.7 & 3.2 & 1.2 & 0.7 \\
\hline 4 & 63.7 & 1.7 & 3.8 & 1.7 & 1.7 & 1.7 \\
\hline 5 & 61.8 & 0.1 & 0.1 & 1.8 & 0.8 & 0.5 \\
\hline 6 & 103.4 & 0.5 & 4.7 & 4.7 & 2.0 & 1.2 \\
\hline 7 & 82.7 & 3.7 & 0.4 & 3.7 & 2.0 & 1.5 \\
\hline 8 & 88.2 & 1.8 & 1.8 & 1.8 & 1.8 & 0.5 \\
\hline 9 & 85.7 & 4.3 & 2.6 & 4.3 & 4.3 & 0.7 \\
\hline 10 & 88.0 & 2.1 & 1.6 & 2.1 & 2.1 & 0.8 \\
\hline$\ldots$ & $\ldots$ & $\ldots$ & $\ldots$ & $\ldots$ & $\ldots$ & $\ldots$ \\
\hline 290 & 97.2 & 1.0 & 1.0 & 10.8 & 3.3 & 1.0 \\
\hline & mean $V r, \mathrm{~km} / \mathrm{h}$ & $M A E_{1}, \mathrm{~km} / \mathrm{h}$ & $M A E_{2}, \mathrm{~km} / \mathrm{h}$ & $M A E_{3}, \mathrm{~km} / \mathrm{h}$ & $M A E_{4}, \mathrm{~km} / \mathrm{h}$ & $M A E_{5}, \mathrm{~km} / \mathrm{h}$ \\
\hline & 83.2 & 2.5 & 2.2 & 4.6 & 2.4 & 1.7 \\
\hline
\end{tabular}

The RMSE (Root Mean Squared Error) is defined as follows:

$$
R M S E_{p}=\sqrt{\frac{1}{M} \sum_{m=1}^{M}\left(V_{p m}-V_{r m}\right)^{2}}
$$

Speed estimation is based on cross-correlation which is a measure of similarity of two series as a function of the displacement of one relative to the other. In Figure 9, the MAE and the RMSE of the estimated speed basing on the series of two AMR sensors distant from each other by $D=90 \mathrm{~cm}$, is presented. 


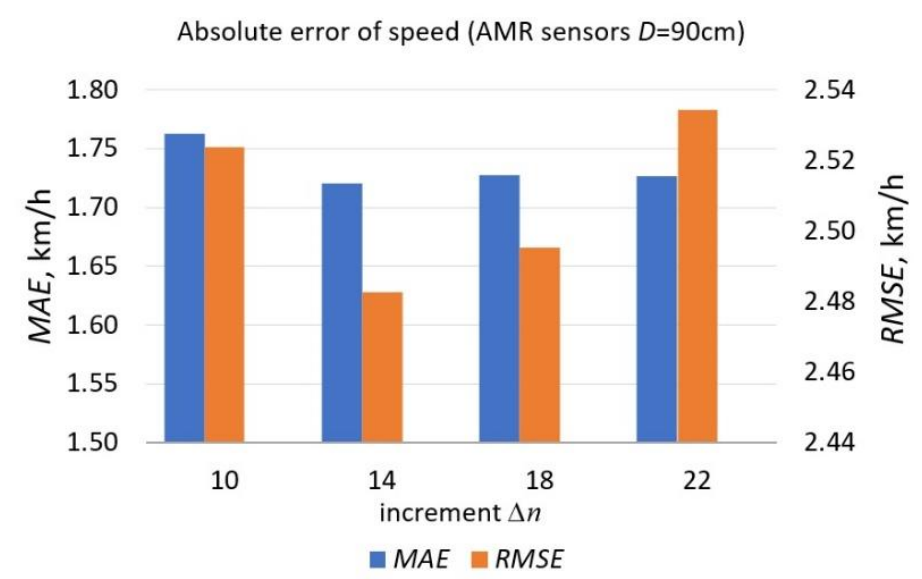

Figure 9. The $M A E$ and the RMSE of the estimated speed and their variability due to increment $\Delta n$.

The chart was created for $M=290$.

As is shown in Table 1, the MAE depends on a pair of sensors location in the system as well as the distance between them. The lowest value $\left(M A E_{5}\right)$ is for $D=90 \mathrm{~cm}$. The lowest results are obtained when calculations are based on the data from $\mathrm{S} 2$ and $\mathrm{S} 3$ sensors $\left(M A E_{3}\right)$. The lowest $M A E$ occurs for the increment $\Delta n=14$ samples. In Table $2 M A E$ values, which were calculated for three speed ranges $(45 \mathrm{~km} / \mathrm{h}-74.99 \mathrm{~km} / \mathrm{h}, 75 \mathrm{~km} / \mathrm{h}-89.99 \mathrm{~km} / \mathrm{h}, 90 \mathrm{~km} / \mathrm{h}-130 \mathrm{~km} / \mathrm{h})$, are presented. Speed ranges are based on the road traffic regulations in different countries for dense built-up areas, outside of dense built-up areas, and on motorways. As it can be seen, the lowest $M A E$ values are for vehicles at speeds within the range of $45 \mathrm{~km} / \mathrm{h}-74.99 \mathrm{~km} / \mathrm{h}$. The $M A E$ is strictly dependent on the speed value.

Table 2. Mean absolute errors of vehicles for three speed ranges and for five different pairs of sensors depicted in Figure 1.

\begin{tabular}{|c|c|c|c|}
\hline Speed Range & $45-74.99 \mathrm{~km} / \mathrm{h}$ & $75-89.99 \mathrm{~km} / \mathrm{h}$ & $90-130 \mathrm{~km} / \mathrm{h}$ \\
\hline$M A E_{1}, \mathrm{~km} / \mathrm{h}$ & 2.0 & 2.7 & 2.6 \\
\hline$M A E_{2}, \mathrm{~km} / \mathrm{h}$ & 1.9 & 2.3 & 2.4 \\
\hline$M A E_{3}, \mathrm{~km} / \mathrm{h}$ & 3.2 & 4.0 & 6.3 \\
\hline$M A E_{4}, \mathrm{~km} / \mathrm{h}$ & 1.8 & 2.2 & 3.1 \\
\hline$M A E_{5}, \mathrm{~km} / \mathrm{h}$ & 1.3 & 1.6 & 2.0 \\
\hline
\end{tabular}

\subsection{Length Estimation Error}

Since the system contains four sensor nodes (Figure 1), a vehicle travel time over each AMR sensor S1-S4 needed to be estimated. For each sensor the number of samples $T_{1}-T_{4}$ in Table 3 represents a period of time between the first maximum and the last minimum of the derivative signal. It is depicted in Figure 7 for sensor S1. 
Table 3. The measured values obtained from four AMR sensors and the geometrical parameters of traveling vehicles.

\begin{tabular}{cccccccccccc}
\hline $\begin{array}{c}\boldsymbol{T}_{\mathbf{1}} \\
\text { Samples }\end{array}$ & $\begin{array}{c}\boldsymbol{T}_{\mathbf{2}} \\
\text { Samples }\end{array}$ & $\begin{array}{c}\boldsymbol{T}_{\mathbf{3}} \\
\text { Samples }\end{array}$ & $\begin{array}{c}\boldsymbol{T}_{\mathbf{4}} \\
\text { Samples }\end{array}$ & $\begin{array}{c}\boldsymbol{V}_{\mathbf{5}} \\
\mathbf{k m} / \mathbf{h}\end{array}$ & $\begin{array}{c}\mathbf{L}_{\mathbf{1}} \\
\mathbf{m}\end{array}$ & $\begin{array}{c}\mathbf{L}_{\mathbf{3}} \\
\mathbf{m}\end{array}$ & $\begin{array}{c}\boldsymbol{V} \boldsymbol{r} \\
\mathbf{k m} / \mathbf{h}\end{array}$ & $\begin{array}{c}\mathbf{L r} \\
\mathbf{m}\end{array}$ & $\begin{array}{c}\boldsymbol{W} \\
\mathbf{m}\end{array}$ & $\begin{array}{c}W / \mathbf{L r} \\
-\end{array}$ & $\begin{array}{c}\mathbf{G} \\
\mathbf{m}\end{array}$ \\
\hline 585 & 506 & 566 & 599 & 88.77 & 7.13 & 6.89 & 87.70 & 4.32 & 2.690 & 0.62 & 0.130 \\
440 & 489 & 442 & 470 & 98.18 & 5.76 & 5.79 & 94.29 & 3.86 & 2.500 & 0.65 & 0.150 \\
368 & 534 & 491 & 370 & 93.91 & 4.76 & 6.34 & 93.04 & 4.59 & 2.625 & 0.57 & 0.119 \\
356 & 391 & 364 & 434 & 93.91 & 4.57 & 4.67 & 92.37 & 4.40 & 2.678 & 0.61 & 0.201 \\
546 & 572 & 564 & 468 & 90.00 & 6.68 & 6.90 & 88.10 & 4.93 & 2.843 & 0.58 & 0.165 \\
577 & 606 & 556 & 659 & 84.16 & 6.53 & 6.29 & 81.49 & 4.32 & 2.694 & 0.62 & 0.150 \\
399 & 406 & 449 & 430 & 81.00 & 4.67 & 5.25 & 84.22 & 4.81 & 2.857 & 0.59 & 0.218 \\
487 & 608 & 576 & 589 & 85.26 & 5.68 & 6.72 & 83.99 & 4.64 & 2.835 & 0.61 & 0.150 \\
479 & 462 & 477 & 541 & 96.72 & 6.46 & 6.43 & 97.03 & 4.82 & 2.854 & 0.59 & 0.155 \\
417 & 390 & 419 & 458 & 102.86 & 5.49 & 5.51 & 94.73 & 4.22 & 2.578 & 0.61 & 0.178 \\
\hline
\end{tabular}

The speed $V_{5}$ is calculated with the use of the cross-correlation method and the derivative data points from sensors S1 and $S 4(D=90 \mathrm{~cm})$. Lengths $L_{1}$ and $L_{3}$ are calculated according to (11). A vehicle is identified by means of a video camera. $L r$ is a reference length, $W$ is a vehicle wheelbase, $G$ is a ground clearance-all these parameters are based on the data from vehicle manufacturers. W/Lr is the wheelbase to length ratio. Lengths $L_{1}$ an $L_{3}$ are defined in meters as follows:

$$
L_{1}=\frac{1000 V_{r} T_{1} t_{s}}{3600}, L_{3}=\frac{1000 V_{r} T_{3} t_{s}}{3600} .
$$

As presented in Table 3 , the differences in samples $T_{1}-T_{4}$ between markers, which indicate the first significant peak and the last one, are quite large. Therefore, $L_{1}$ and $L_{3}$ are usually not equal. Lengths and their errors were computed using $T_{1}$ and $T_{3}$ data from sensor nodes S1 and S3. However, it is possible to obtain a result as their average or even the average of $T_{1}-T_{4}$. However, it would lengthen the processing time of a vehicle. This is unwanted, especially for long vehicles travelling at slow speeds. Errors based on S3 are larger than S1 (Figure 10). The MAE measures of $L_{1}$ and $L_{3}$ are defined in the following way:

$$
M A E_{L 1}=\frac{1}{M} \sum_{m=1}^{M}\left|L_{1 m}-L_{r m}\right|, M A E_{L 3}=\frac{1}{M} \sum_{m=1}^{M}\left|L_{3 m}-L_{r m}\right| .
$$

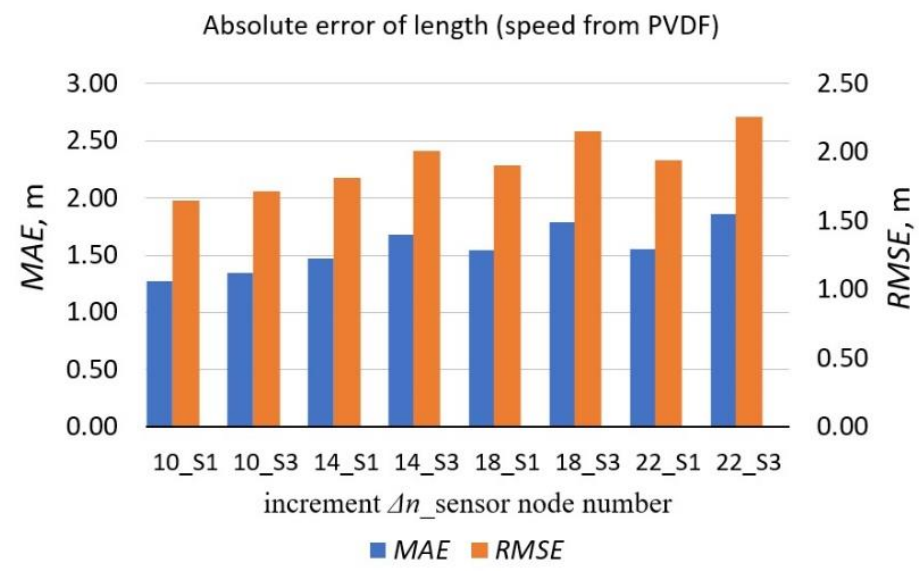

Figure 10. The MAE and the RMSE of estimated lengths $L_{1}$ and $L_{3}$ and their dependence on the increment $\Delta n$ when calculating the difference quotient from the change in magnetic field magnitude data points. Calculations were based on the speed readings from PVDF sensors. The chart was made for $M=290$. 
When $V r$ speed was used in (11), the lowest value of $M A E$ was for the increment $\Delta n=10$ samples but the error differences, in comparison to $\Delta n=14,18,22$, were small.

When the speeds from AMR sensors data were used in (11) and the sensors were $60 \mathrm{~cm}$ or $90 \mathrm{~cm}$ distant from each other, the obtained length errors were up to $8 \%$ lower in comparison to the $30 \mathrm{~cm}$ distance (Figure 11). The highest $M A E$ was about $1.9 \mathrm{~m}$. Finally, the vehicles were divided into five classes according to their length. It is difficult to find one unified vehicle classification in the world. There are commonly used terms of vehicles market segments with or without the number of axles [17]. There are also legal classifications based on interior volume index or gross vehicle weight rating. We decided to calculate the mean $W / L r$ ratio for every vehicle class and present it in Table 4 . For the longest vehicles, it is noticeably larger.

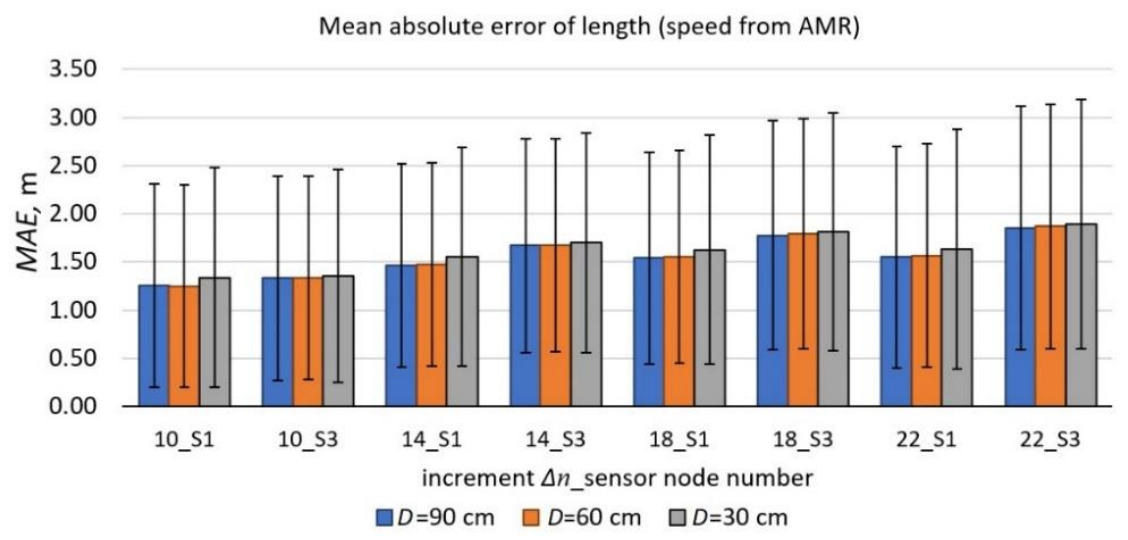

Figure 11. The $M A E$ of estimated lengths $L_{1}$ and $L_{3}$ and their dependence on the increment $\Delta n$ when calculating a numerical derivative from the change in the magnetic field magnitude data points. Calculations were based on the speed readings from AMR sensors. The chart was made for $M=290$. The error bars represent the $68 \%$ confidence interval of the mean absolute error $(M A E)$.

Table 4. Vehicle classification according to their reference length $L r$ and determination of the mean parameter $W / L r$ value.

\begin{tabular}{cccccc}
\hline class & A & B & C & D & E \\
\hline & $\begin{array}{c}L r \geq 3.5 \text { and } \\
L r<4.5 \mathrm{~m}\end{array}$ & $\begin{array}{c}L r \geq 4.5 \text { and } \\
L r<4.7 \mathrm{~m}\end{array}$ & $\begin{array}{c}L r \geq 4.7 \text { and } \\
L r<5.2 \mathrm{~m}\end{array}$ & $\begin{array}{c}L r \geq 5.2 \text { and } \\
L r<8.0 \mathrm{~m}\end{array}$ & $L r \geq 8.0 \mathrm{~m}$ \\
\hline $\max W / L r$ & 0.66 & 0.61 & 0.61 & 0.69 & 0.89 \\
$\min W / L r$ & 0.57 & 0.56 & 0.56 & 0.54 & 0.53 \\
$\operatorname{mean} W / L r$ & 0.61 & 0.59 & 0.58 & 0.62 & 0.71 \\
\hline
\end{tabular}

In Table 5, the $M A E$ values are presented for every class and for all classes together. Additionally, for classes A, B, C, the influence of the ground clearance $G$ with $W / L r$ is analyzed and special cases are selected to highlight the differences. 
Table 5. The MAE of the estimated lengths $L_{1}$ and $L_{3}$ of all vehicles from a given class and the values of these errors for two wheelbase to the length $W / L r$ ratio intervals (lower and upper than the mean) and three ground clearance $G$ intervals.

\begin{tabular}{|c|c|c|c|c|c|}
\hline \multicolumn{6}{|c|}{ class A-city cars, small passenger cars, compact SUVs } \\
\hline Error $(\mathrm{m})$ & $\begin{array}{l}\text { all } W / L r \\
\text { all } G\end{array}$ & $\begin{array}{c}\text { all } W / L r \\
G \leq 0.13 \mathrm{~m}\end{array}$ & $\begin{array}{c}\text { all } W / L r \\
G \geq 0.18 \mathrm{~m}\end{array}$ & $\begin{array}{c}W / L r<0.61 \\
\text { all } G\end{array}$ & $\begin{array}{l}W / L r<0.61 \\
G \leq 0.13 \mathrm{~m}\end{array}$ \\
\hline$M A E_{L 1}$ & 1.14 & 1.16 & 1.37 & 1.31 & 1.22 \\
\hline$M A E_{L 3}$ & 1.49 & 1.66 & 1.39 & 1.62 & 1.83 \\
\hline \multicolumn{6}{|c|}{ class B-family cars, mid-size SUVs } \\
\hline Error $(\mathrm{m})$ & $\begin{array}{l}\text { all } W / L r \\
\text { all } G\end{array}$ & $\begin{array}{c}\text { all } W / L r \\
G \leq 0.13 \mathrm{~m}\end{array}$ & $\begin{array}{c}\text { all } W / L r \\
G \geq 0.18 \mathrm{~m}\end{array}$ & $\begin{array}{c}W / L r \geq 0.59 \\
\text { all } G\end{array}$ & $\begin{array}{l}W / L r \geq 0.59 \\
G \geq 0.18 \mathrm{~m}\end{array}$ \\
\hline$M A E_{L 1}$ & 1.30 & 1.20 & 1.74 & 1.65 & 1.87 \\
\hline$M A E_{L 3}$ & 1.58 & 1.15 & 2.10 & 1.52 & 2.23 \\
\hline \multicolumn{6}{|c|}{ class C-executive cars, luxury cars, large SUVs } \\
\hline Error $(\mathrm{m})$ & $\begin{array}{l}\text { all } W / L r \\
\text { all } G\end{array}$ & $\begin{array}{c}\text { all } W / L r \\
G \leq 0.13 \mathrm{~m}\end{array}$ & $\begin{array}{c}\text { all } W / L r \\
G \geq 0.18 \mathrm{~m}\end{array}$ & $\begin{array}{l}W / L r \geq 0.58 \\
G \leq 0.13 \mathrm{~m}\end{array}$ & $\begin{array}{l}W / L r \geq 0.58 \\
G \geq 0.18 \mathrm{~m}\end{array}$ \\
\hline$M A E_{L 1}$ & 0.96 & 0.51 & 1.95 & 0.44 & 1.92 \\
\hline$M A E_{L 3}$ & 1.05 & 0.66 & 2.06 & 0.49 & 2.06 \\
\hline & class D & class E & \multicolumn{3}{|c|}{ all classes of vehicles (A, B, C, D, E) } \\
\hline Error (m) & $\begin{array}{l}\text { all } W / L r \\
\text { all } G\end{array}$ & $\begin{array}{l}\text { all } W / L r \\
\text { all } G\end{array}$ & $\begin{array}{l}\text { all } W / L r \\
\text { all } G\end{array}$ & $\begin{array}{l}W / L<0.61 \\
\quad \text { all } G\end{array}$ & $\begin{array}{l}W / L r \geq 0.61 \\
\quad \text { all } G\end{array}$ \\
\hline$M A E_{L 1}$ & 1.95 & 2.89 & 1.48 & 1.21 & 2.06 \\
\hline$M A E_{L 3}$ & 2.16 & 2.93 & 1.68 & 1.40 & 2.27 \\
\hline
\end{tabular}

Class B, column 6-ANs: Volkswagen Sharan, Ford Galaxy, etc.; class C, column 5-sedans and wagons: BMW 5, Mercedes-Benz E cl., VW Passat, etc.; class C, column 6-large SUVs: Volvo XC90, Porsche Cayenne, Mercedes-Benz $\mathrm{M}$ cl., etc.; class D—large VANs, minibuses; class E—-three or more axle vehicles, buses.

As is shown in Table 6, the adaptive method based on differentiating signals causes a minor decrease of the $M A E$ values compared to a fixed threshold-based method [6]. It is especially noticeable for the vehicles with $W / L r \geq 0.61$. However, for the vehicles with $W / L r<0.61$, a fixed threshold $\mathrm{HT}=0.06 \mathrm{mT}$ the $M A E$ values are the lowest.

Table 6. The MAE of estimated lengths $L_{1}$ and $L_{3}$ of all vehicles-comparison of two methods.

\begin{tabular}{cccc}
\hline \multicolumn{4}{c}{ all classes of vehicles $(\mathrm{A}, \mathrm{B}, \mathrm{C}, \mathrm{D}, \mathrm{E})$} \\
\hline $\begin{array}{c}\text { all } W / \mathrm{Lr} \\
\text { all } G\end{array}$ & $\begin{array}{c}W / L<0.61 \\
\text { all } G\end{array}$ & $\begin{array}{c}W / L r \geq 0.61 \\
\text { all } G\end{array}$ \\
\hline fixed threshold-based method (signals not differentiated, $\mathrm{HT}=0.03 \mathrm{mT})$ \\
\hline$M A E_{L 1}$ & 1.76 & 1.54 & 2.17 \\
$M A E_{L 3}$ & 1.75 & 1.55 & 2.13 \\
\hline fixed threshold-based method (signals not differentiated, HT $=0.06 \mathrm{mT})$ \\
\hline$M A E_{L 1}$ & 1.43 & 1.00 & 2.44 \\
$M A E_{L 3}$ & 1.42 & 0.95 & 2.57 \\
\hline adaptive two-extreme-peak detection method (signals differentiated, $\Delta n=14, \mathrm{HT}=0.1 \mathrm{hdsp})$ \\
\hline$M A E_{L 1}$ & 1.48 & 1.21 & 2.06 \\
$M A E_{L 3}$ & 1.68 & 1.40 & 2.27 \\
\hline
\end{tabular}

The data in the tables is presented without calibration correction factors. This means that these error values can be reduced. 


\subsection{Correction Factor of Estimated Length}

All results obtained from formula (11) were multiplied by the appropriate correction factor $\mathrm{C}_{f}$ to reduce $M A E$ :

$$
M A E_{L 1}=\frac{1}{M} \sum_{m=1}^{M}\left|C_{f} \cdot L_{1 m}-L_{r m}\right| .
$$

The dependence of the threshold and the correction factor on the $M A E_{L 1}$ is presented in Figure 12. These parameters need to be selected precisely.

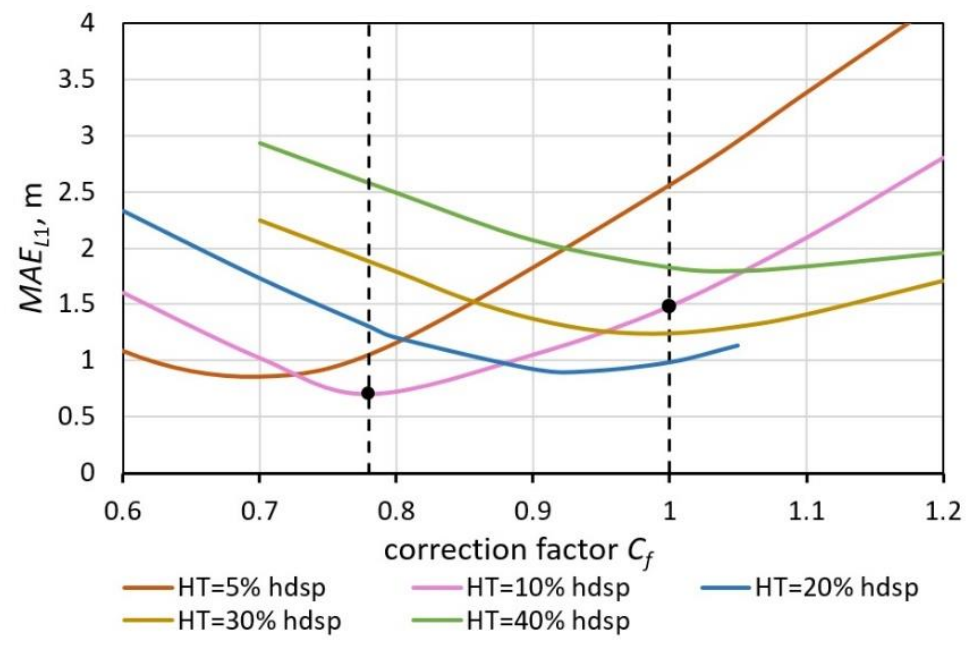

Figure 12. The $M A E$ of estimated lengths $L_{1}$ and their dependence on the correction factor $C_{f}$ and threshold HT as a percentage of the highest derivative signal peak. The $M A E$ is presented for all classes of vehicles $M=290$, the signals were smoothed with a $100 \mathrm{~Hz}$ low-pass filter.

Minimum absolute error values were found for $\mathrm{C}_{f}=0.78$ and threshold $\mathrm{HT}=0.1$ hdsp (hdsp-the highest derivative signal peak). As a result, about $50 \%$ error reduction was achieved (Table 7).

Table 7. The $M A E$ of estimated lengths $L_{1}$ and $L_{3}$ of all vehicles after multiplying by $C_{f}=0.78$.

\begin{tabular}{cccc}
\hline \multicolumn{4}{c}{ all classes of vehicles $(\mathrm{A}, \mathrm{B}, \mathrm{C}, \mathrm{D}, \mathrm{E})$} \\
\hline Error $(\mathrm{m})$ & all $W / L r$ & $W / L<0.61$ & $W / L r \geq 0.61$ \\
& all $G$ & all $G$ & all $G$ \\
\hline \multicolumn{2}{c}{ adaptive two-extreme-peak detection method (signals differentiated, $\Delta n=14, \mathrm{HT}=0.1$ hdsp) } \\
\hline$M A E_{L 1}$ & 0.70 & 0.64 & 0.80 \\
$M A E_{L 3}$ & 0.75 & 0.67 & 0.92 \\
\hline
\end{tabular}

\subsection{Summary}

The speed estimation error depends on many factors. One of them is the signal processing technique used. The variability of errors due to the increment $\Delta n$ when calculating difference quotients is noticeable in Figure 9. Moreover, since the speed is calculated with the use of the cross-correlation function, decreasing the sample size of the processed signals (number of data points) may lead to higher error values. Another factor is the sensor deployment on a road lane. The $M A E$ is the lowest $(1.7 \mathrm{~km} / \mathrm{h})$ for AMR sensors deployed at the largest distance of $90 \mathrm{~cm}$ (Table 1). The MAE is also the lowest at the speed range of $45 \mathrm{~km} / \mathrm{h}-74.99 \mathrm{~km} / \mathrm{h}$ (Table 2). It is related to discretization, described in Section 2.1.

The length of a vehicle (11) is estimated based on the time differences between markers (Figure 7) and previously evaluated speed. Every normalized derivative curve contains many peaks, which may be lower or higher. The most important activity which affects accuracy is to setup the adequate 
threshold. The best results are observed when the calculated length is based on the output data from sensor S1 (Table 3). The errors of the estimated lengths $L_{1}$ and $L_{3}$ and their dependence on $\Delta n$ when calculating numerical derivative from the change in the magnetic field magnitude data points are presented in Figures 10 and 11. The $M A E$ is the lowest when $\Delta n=10$ samples and $D=90 \mathrm{~cm}$.

Finally, the vehicles were divided into 5 classes. The $M A E$ of the estimated lengths of all vehicles from a given class and the values of these errors for two wheelbase to the length $W / L r$ ratio intervals (lower and upper than the mean for every class) and two ground clearance $G$ intervals are presented in Table 5. These values are from $0.44 \mathrm{~m}$ to $2.93 \mathrm{~m}$. This range is from $0.52 \mathrm{~m}$ to $1.18 \mathrm{~m}$ when using the appropriate calibration factor. The most significant difference is visible between Class $C$ vehicles with $G \leq 0.13 \mathrm{~m}$ (sedans and wagons) and $G \geq 0.18 \mathrm{~m}$ (large SUVs). The largest values are for the longest $\mathrm{D}$ and $E$ class vehicles in comparison with $\mathrm{A}, \mathrm{B}, \mathrm{C}$ class passenger cars. Differences of $M A E_{\mathrm{L} 1}$ and $M A E_{\mathrm{L} 3}$ for the same $W / L r$ and $G$ sometimes even reach $40 \mathrm{~cm}$.

The adaptive method based on differentiating signals causes a minor decrease of the $M A E$ values compared to a fixed threshold-based method. It should be noted that one of the most important parameters is $\Delta n$, which should be 14 samples for our data. The appropriate correction factor $C_{f}$ is also needed. There is almost no vehicle acceleration or deceleration effect on the $M A E$ because the distance between sensors is small (max. $90 \mathrm{~cm}$ ). On the other hand, there is rather no possibility to enlarge the sampling frequency. There are few digital three-axis sensors, i.e., LIS3MDL, HMC5983, LSM9DS1 and other commercial off-the-shelf products [18] with fast output rate (ODR > $80 \mathrm{~Hz}$ ) setting.

\section{Conclusions}

Effective traffic management schemes that improve traffic flow and utilization of road infrastructure are very important at present times [19,20]. Magnetic sensors have advantages over other non-contact based sensing techniques because the weather conditions do not affect the efficiency of vehicle detection [21,22]. In the literature, the following features are indicated: the low price of detectors and simplicity of their installation. It is possible to identify the type of vehicle (car, bus, truck) because they differ in the degree of the interference field. Therefore, it seems to be necessary to create an intelligent network of sensors that acquire the changes in the Earth magnetic field magnitude. In some literature only one or two sensors are applied roadway or roadside $[23,24]$. They usually are used to measure vehicle speed or to detect presence of a traveling vehicle using novel algorithms [25].

The presented system contains four AMR sensors to estimate the length of vehicles. The performed research is a preliminary step before vehicle classification [26]. The piezoelectric sensors (PVDF) were used as the reference system. Based on the data from PVDF sensors, we can know precisely the number of vehicle axles and estimate wheelbases, i.e., the distance between the centers of the front and rear axles. Magnetic sensors generate more information if it is necessary to discern cars of the same class, e.g., between a sedan and an SUV. They both may have the same length and wheelbase, but height of the peaks and their location in their magnetic signatures are usually different. Ultimately, we plan that our system will work with AMR sensors only.

Errors of speed and length estimation presented in Tables 1,2 and 5-7 are mostly the result of the imperfect trajectory of a traveling vehicle over sensors, the different construction and geometry of vehicles, the presence of ferromagnetic loads, which may be carried in trucks with trailers, the discretization of the acquired data and the noise in signals. It is worth pointing out that the visual identification of brand and model of a traveling vehicle is based on a video image and the manufacturer's data. The type of a vehicle and yawing are taken into account, but the vehicle load can change the length evaluation process.

The $M A E$ values of the estimated speed are from 1.3 to $6.3 \mathrm{~km} / \mathrm{h}$. They depend on the distance between sensors, speed of vehicle and the filtering signals method used. As a comparison, the errors for variously constructed systems with magnetic sensors placed on the road lane at a distance $D=6 \mathrm{~m}$ are $R M S E=5.1 \mathrm{~km} / \mathrm{h}, M A P E=2.65 \%$ (MAPE - Mean Absolute Percentage Error) [27], and at a distance of $20 \mathrm{~cm} M A P E=4.16 \%$ or $2.10 \%$ [28]. With regards to the system with induction loops, in publication [29], 
accuracy measures were given for four categories of vehicles: RMSE-from $2.5 \mathrm{~km} / \mathrm{h}$ to $8.6 \mathrm{~km} / \mathrm{h}$, MAPE-from $1.8 \%$ to $9 \%$.

As we can see in Table 5, the lowest $M A E$ of the estimated length occurred for $\mathrm{C}$ class sedans and wagons $(0.44 \mathrm{~m})$. The $M A E$ for the longest car is about $8.5 \%(5.2 \mathrm{~m})$. The vehicle clearance $G$ has its influence on the result, e.g., if we compare $M A E$ values in columns 5 and 6 of class $C$. The largest relative $M A E$ error is observed for class $\mathrm{D}$, i.e., large VANs and minibuses. That means it equals to $25 \%$ with an average length of $7 \mathrm{~m}$ to $8 \mathrm{~m}$. When the correction factor is used the relative error is $9.75 \%$. The comparable error values are given in publication [30]; however, in our system the sampling frequency is five times higher, the distance $D$ is 10 times shorter and the number of sensor nodes is eight times less.

With regards to designing a reliable transportation system, the AMR sensors are an alternative choice to magneto-impedance sensors [19], other magnetic field sensors and inductive loops. They are dedicated to measure small magnetic fields (a few $\mathrm{mT}$ ). Due to their small size, low cost and low detection limit (nT), they are suitable for communication systems and mobile applications [2]. They can also be considered suitable to be installed in areas where inductive loops cannot be cut in the road surface [12].

Author Contributions: Conceptualization: V.M., D.N. and D.M.; Methodology: D.A. and A.I.; Software: D.N. and D.M.; Validation: A.I., D.A., A.V. and M.Z.; Visualization: V.M., A.I., D.M. and W.W.; Investigation: V.M., D.N., D.A., A.V. and M.Z.; Resources: M.Z.; Data Curation: D.N.; Writing-Original Draft Preparation: A.I., D.M., D.A. and M.C.; Writing-Review and Editing: A.I., D.A. and W.W.; Supervision: V.M.; Project Administration: D.A.; Funding Acquisition: A.V. and M.Z.

Funding: This research received no external funding.

Conflicts of Interest: The authors declare no conflict of interest.

\section{References}

1. Guerrero-Ibanez, J.; Zeadally, S.; Contreras-Castillo, J. Sensor Technologies for Intelligent Transportation Systems. Sensors 2018, 18, 1212. [CrossRef] [PubMed]

2. Hott, M.; Hoeher, P.A.; Reinecke, S.F. Magnetic Communication Using High-Sensitivity Magnetic Field Detectors. Sensors 2019, 19, 3415. [CrossRef] [PubMed]

3. Nishibe, Y.; Ohta, N. Thin Film Magnetic Field Sensor Utilizing Magneto Impedance Effect. $R$ D Rev. Toyota CRDL 2000, 35, 1-7. [CrossRef]

4. Nishibe, Y.; Ohta, N.; Tsukada, K.; Yamadera, H.; Nonomura, Y.; Mohri, K.; Uchiyama, T. Sensing of Passing Vehicles Using a Lane Marker on a Road With Built-In Thin-Film MI Sensor and Power Source. IEEE Trans. Veh. Technol. 2004, 53, 1827-1834. [CrossRef]

5. Belenguer, F.M.; Salcedo, A.M.; Ibanez, A.G.; Sánchez, V.M. Advantages offered by the double magnetic loops versus the conventional single ones. PLoS ONE 2019, 14, e0211626. [CrossRef]

6. Hu, Y.; Kang, W.; Fang, Y.; Xie, L.; Qiu, L.; Jin, T. Piezoelectric Poly(vinylidene fluoride) (PVDF) Polymer-Based Sensor for Wrist Motion Signal Detection. Appl. Sci. 2018, 8, 836. [CrossRef]

7. Burnos, P.; Rys, D. The Effect of Flexible Pavement Mechanics on the Accuracy of Axle Load Sensors in Vehicle Weigh-in-Motion Systems. Sensors 2017, 17, 2053. [CrossRef]

8. Gajda, J.; Burnos, P.; Sroka, R. Accuracy Assessment of Weigh-in-Motion Systems for Vehicle's Direct Enforcement. IEEE Intell. Transp. Syst. Mag. 2018, 10, 88-94. [CrossRef]

9. Markevicius, V.; Navikas, D.; Idzkowski, A.; Valinevicius, A.; Zilys, M.; Andriukaitis, D. Vehicle Speed and Length Estimation Using Data from Two Anisotropic Magneto-Resistive (AMR) Sensors. Sensors 2017, 17, 1778. [CrossRef]

10. Markevicius, V.; Navikas, D.; Idzkowski, A.; Andriukaitis, D.; Valinevicius, A.; Zilys, M. Practical Methods for Vehicle Speed Estimation Using a Microprocessor-Embedded System with AMR Sensors. Sensors 2018, 7, 2225. [CrossRef]

11. Markevicius, V.; Navikas, D.; Idzkowski, A.; Valinevicius, A.; Zilys, M.; Janeliauskas, A.; Walendziuk, W.; Andriukaitis, D. An Effective Method of Vehicle Speed Evaluation in Systems Using Anisotropic Magneto-Resistive Sensors. IEEE Intell. Transp. Syst. Mag. 2019. [CrossRef] 
12. Klein, L.A.; Mills, M.K.; Gibson, D.R.P. Traffic Detector Handbook: Third Edition-Volume I; Federal Highway Administration: McLean, VA, USA, 2006.

13. Bozuyla, M.; Tola, A.T.; Murat, Y.S. A Novel Safe Merging Algorithm for Connected Vehicles Using NetLogo. Elektron. Elektrotechnika 2018, 24, 3-7. [CrossRef]

14. Bokare, P.S.; Maurya, A.K. Acceleration-Deceleration Behaviour of Various Vehicle Types. Transp. Res. Procedia 2017, 25, 4733-4749. [CrossRef]

15. Misra, R.; Bora, A.; Dewangan, G. Estimation of error on the cross-correlation, phase and time lag between evenly sampled light curves. Astron. Comput. 2018, 23, 83-91. [CrossRef]

16. Tamim, N.S.M.; Ghani, F. Techniques for Optimization in Time Delay Estimation from Cross Correlation Function. Int. J. Eng. Technol. IJET-IJENS 2010, 10, 69-75.

17. Hoeschen, B.; Erker, M.; Janson, B.; Medland, R. Best Practices Guidebook: Collecting Short Duration Manual Vehicle Classifications Counts on High Volume Urban Facilities; Federal Highway Administration: Denver, CO, USA, 2005.

18. Schulz, L.; Heinisch, P.; Richter, I. Calibration of Off-the-Shelf Anisotropic Magnetoresistance Magnetometers. Sensors 2019, 8, 1850. [CrossRef]

19. Honkura, Y.; Yamamoto, M.; Hamada, N.; Shimode, A. Magneto-Sensitive Wire, Magneto-Impedance Element and Magneto-Impedance Sensor. Eur. Pat. Appl. EP2276082A1, 2009.

20. Thakur, A.; Malekian, R. Fog Computing for Detecting Vehicular Congestion, an Internet of Vehicles Based Approach: A Review. IEEE Intell. Transp. Syst. Mag. 2019, 11, 8-16. [CrossRef]

21. Bugdol, M.; Segiet, Z.; Krecichwost, M.; Kasperek, P. Vehicle detection system using magnetic sensors. Transp. Probl. 2014, 9, 49-60.

22. Grzechca, D.; Rybka, P.; Paszek, K. Evaluation of the Accuracy of ADAS Module Readings Based on an Analysis of the Transient Supply Current and Neural Network Application. Elektron. Elektrotechnika 2018, 24, 46-52. [CrossRef]

23. Sarcevic, P.; Pletl, S. False Detection Filtering Method for Magnetic Sensor-Based Vehicle Detection Systems. In Proceedings of the 6th IEEE International Symposium on Intelligent Systems and Informatics, SISY 2018, Subotica, Serbia, 13-15 September 2018; pp. 277-281. [CrossRef]

24. Xu, C.; Wang, Y.; Bao, X.; Li, F. Vehicle classification using an imbalanced dataset based on a single magnetic sensor. Sensors 2018, 18, 1690. [CrossRef] [PubMed]

25. Dong, H.; Wang, X.; Zhang, C.; He, R.; Jia, L.; Qin, Y. Improved Robust Vehicle Detection and Identification Based on Single Magnetic Sensor. IEEE Access 2018, 6, 5247-5255. [CrossRef]

26. Chen, X.; Kong, X.; Xu, M.; Sandrasegaran, K.; Zheng, J. Road Vehicle Detection and Classification Using Magnetic Field Measurement. IEEE Access 2019, 7, 52622-52633. [CrossRef]

27. Balid, W.; Tafish, H.; Refai, H.H. Intelligent Vehicle Counting and Classification Sensor for Real-Time Traffic Surveillance. IEEE Trans. Intell. Transp. Syst. 2018, 19, 1784-1794. [CrossRef]

28. Kwon, Y.J.; Kim, D.H.; Choi, K.H. A single node vehicle detection system using an adaptive signal adjustment technique. In Proceedings of the 20th International Symposium on Wireless Personal Multimedia Communications (WPMC), Bali, Indonesia, 17-20 December 2017; pp. 349-353.

29. Mielczarek, M.; Gajda, J. Individual vehicle speed estimation on the base of magnetic profile analysis —Estymacja indywidualnej prędkości pojazdu na podstawie analizy profilu magnetycznego. Prz. Elektrotechniczny 2015, 3, 186-189. [CrossRef]

30. Velisavljevic, V.; Cano, E.; Dyo, V.; Allen, B. Wireless Magnetic Sensor Network for Road Traffic Monitoring and Vehicle Classification. Transp. Telecommun. 2016, 17, 274-288. [CrossRef]

(C) 2019 by the authors. Licensee MDPI, Basel, Switzerland. This article is an open access article distributed under the terms and conditions of the Creative Commons Attribution (CC BY) license (http://creativecommons.org/licenses/by/4.0/). 